\title{
OXIDATION-REDUCTION POTENTIAL IN SEA WATER
}

\author{
By L. H. N. Cooper, Ph.D., F.I.C.
}

Assistant Chemist at the Plymouth Laboratory

In bacteriological studies much attention is now given to oxidation-reduction potentials. The systems studied have usually potentials at least $0.4 \mathrm{~V}$. below that of the reversible oxygen electrode, are reasonably well poised and obey laws thermodynamically deduced. Owing to the irreversibility of the oxygen electrode and to difficulties of measurement no such attention has been given to oxidation-reduction potentials in sea water or other aerated natural waters. Nevertheless, such waters can exert a potential which may be of considerable biological, geological and industrial importance.

One record only of the oxidation-reduction potential of sea water was found in the literature, $0.25 \mathrm{~V}$. recorded incidentally by Reiss \& Vellinger (1929) in the course of a study of sea-urchin eggs. Of the $2 \mathrm{mg}$./1. of organic carbon which Keys, Cristensen \& Krogh (1935) have found in sea water, practically nothing is known beyond the fact that it is somewhat inert, how inert we do not know. Since the oxidation-reduction system based on dissolved oxygen appears to be much the most likely to be that giving poise to the water, a theoretical examination of the system was made. Certain thermodynamic properties of sea water, a knowledge of which is required for other investigations, are also treated at some length.

The reaction at an oxygen electrode is:

$$
\mathrm{O}_{2}+2 \mathrm{H}_{2} \mathrm{O}+4 \epsilon=4 \mathrm{OH}^{-} \text {. }
$$

If this reaction can take place reversibly, in the thermodynamic sense, the oxidation-reduction potential of any oxygen electrode, $\mathrm{E}^{\mathrm{h}}$, will be given by

$$
\mathrm{E}^{\mathrm{h}}=\mathrm{E}^{\circ}-\frac{\mathrm{RT}}{4 \mathrm{~F}} \ln \frac{a_{\mathrm{OH}^{-}}{ }^{4}}{a_{\mathrm{O}_{2}}} .
$$

$\mathrm{E}^{\circ}$ is the potential, relative to the normal hydrogen electrode, which should be realized at an inert metal electrode saturated with oxygen at I atm. pressure acting in an electrolyte containing hydroxyl-ion at unit activity (nearly equi-

* On modern chemical theory a uni-univalent strong electrolyte, dissolved in water, dissociates practically completely into ions each having concentration, $m_{x}$. Owing to electrostatic forces between the ions, not all at any instant are able to participate actively in chemical reactions. That part which can do so is termed the activity, $a_{x}$, and is related to the concentra tion by the activity coefficient, $\gamma_{x}$ :

$$
a_{x}=\gamma_{x} m_{x} .
$$

Activity and concentration are measured in the same units. The activity coefficient is a number without dimensions. The activity concept is used wherever it applies so that, for instance, $K_{v}$ is defined in terms of activities and not, as in most of the earlier work, in terms of concentrations. The system of notation here followed is that of Lewis \& Randall (1923). 
valent to a normal solution of sodium hydroxide). For reasons which will be made clear below, this standard potential of the oxygen electrode is not realizable in practice.

Equation (I) may be rewritten

$$
\mathrm{E}^{\mathrm{h}}=\mathrm{E}^{\circ}-\frac{\mathrm{RT}}{\mathrm{F}} \ln \frac{a_{\mathrm{OH}^{-}}}{\sqrt[4]{p_{0}}},
$$

so that to evaluate $\mathrm{E}^{\mathrm{h}}$ we need to know $\mathrm{E}^{\circ}, p_{0}$ and $a_{\mathrm{OH}^{-}}$. These quantities will be examined in turn.

\section{The Standard Oxygen Electrode Potential, $\mathrm{E}^{\circ}$}

At $25^{\circ}$ C. $\mathrm{E}^{\circ}$ has been calculated to be $0.3976 \mathrm{~V}$. (Lewis \& Randall, I923, p. 487 ). For other temperatures $E^{\circ}$ has been computed from the free energies of formation, and of ionization, of water. We may write three thermodynamic equations, where $\Delta F_{T}^{\circ}$ represents the increase in free energy of the system concerned with reference to the standard states of the components at the temperature $T^{\circ}$ abs.:

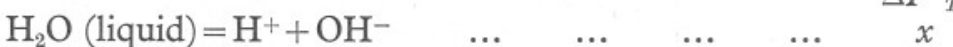

$$
\begin{aligned}
& \mathrm{H}_{2} \text { (gas) }+\frac{1}{2} \mathrm{O}_{2} \text { (gas) }=\mathrm{H}_{2} \mathrm{O} \text { (liquid) } \quad \ldots \quad \ldots . \quad \ldots . \quad \ldots
\end{aligned}
$$

Multiplying (3) by 2, adding (4) and (5) and then dividing by 2 we get

$$
\frac{1}{4} \mathrm{O}_{2} \text { (gas) }+\frac{1}{2} \mathrm{H}_{2} \mathrm{O} \text { (liquid) }=\mathrm{OH}^{-} \quad \ldots \quad \ldots \quad \ldots \quad \ldots \quad x+\frac{y}{2}
$$

From equation (6) $\mathrm{E}^{\circ}{ }_{T}$ may be calculated by means of (7):

$$
\mathrm{E}_{T}^{\circ}=-\frac{\Delta F_{T}^{\circ}}{\mathrm{F}} \text {. }
$$

According to International Critical Tables, Vol. viI, p. 232, the free energy of ionization, $x$, at any temperature, $T^{\circ}$ abs., may be calculated from the relation

$$
x=29210+53 \ln T-335 \cdot 86 T \text {. }
$$

Similarly, the free energy of formation

$$
y=-70650-8 \cdot 0 \ln T+92 \cdot 84 T \text {. }
$$

From these data the free energy changes and electrode potentials relevant to equation (6) have been calculated at temperatures between $0^{\circ}$ and $25^{\circ} \mathrm{C}$. (Table I). Thus the value of $\mathrm{E}^{\circ}$ decreases linearly by $0.00 \mathrm{I} 6 \mathrm{~V}$./degree.

Table I

\begin{tabular}{ccccc} 
& & & \multicolumn{2}{c}{ Oxygen system, equation (6) } \\
$t^{\circ} \mathrm{C}$. & $x$ cal. & $y / 2 \mathrm{cal}$. & $\Delta F^{\circ}=x+y / 2 \mathrm{cal}$. & $\mathrm{E}^{\circ}$ \\
0 & +18684 & -28775 & -10091 & +0.4373 \\
5 & +18760 & -28676 & -9916 & +0.4298 \\
I0 & +18843 & -28576 & -9733 & +0.4218 \\
15 & +18926 & -28476 & -9550 & +0.4139 \\
20 & +19013 & -28379 & -9366 & +0.4059 \\
25 & +19105 & -28280 & -9175 & +0.3976
\end{tabular}




\section{Oxygen Activity or Partial Pressure, $p_{0}$}

Due to the presence of water vapour the partial pressure of oxygen in saturated air varies slightly, but for our present purpose it is sufficient to take a round figure, $0.206 \mathrm{~atm}$., for the partial pressure of oxygen over the sea. The partial pressure of oxygen in sea water at $100 \%$ saturation must be identical with this and measures the oxygen activity. Sea water at various degrees of oxygen saturation will therefore have the following values of $p_{0}$ and $\sqrt[4]{p_{0}}$ :

\begin{tabular}{cll}
$\%$ saturation & \multicolumn{1}{c}{$p_{0}$} & $\sqrt[4]{p_{0}}$ \\
I00 & 0.206 & 0.674 \\
50 & 0.103 & 0.567 \\
I0 & 0.0206 & 0.379 \\
I & 0.0021 & 0.213
\end{tabular}

\section{The Thermodynamic Ionic Product, $K_{w}$, And Hydroxyl-Ion ACTIVITY, $a_{\mathrm{OH}^{-}}$}

The thermodynamic ionic product, $K_{w}=\frac{a_{\mathrm{H}^{+}} a_{\mathrm{OH}^{-}}}{a_{\mathrm{H}_{2} \mathrm{O}}}$, is independent of the presence of solutes, and in consequence in sea water the product of the activities of hydrogen and hydroxyl ions is the same as in pure water except in so far as the presence of salts alters the activity of the undissociated water. However, in moderately concentrated solutions of strong electrolytes, the product of the activity coefficients, $\gamma_{\mathrm{H}^{+}} \gamma_{\mathrm{OH}^{-}}$, decreases so that in a solution of sodium chloride, having the same ionic strength as sea water, $\gamma_{\mathrm{H}^{+}} \gamma_{\mathrm{OH}^{-}}=0.5 \mathrm{I}$. Therefore

$$
m_{\mathrm{H}^{+}} m_{\mathrm{OH}^{-}}=\frac{K_{w} a_{\mathrm{H}_{2} \mathrm{O}}}{\gamma_{\mathrm{H}^{+}} \gamma_{\mathrm{OH}^{-}}}=\frac{K_{w} a_{\mathrm{H}_{2} \mathrm{O}}}{0.5 \mathrm{I}}
$$

that is, if we assume for the moment that the activity of the water $a_{\mathrm{H}_{2} \mathrm{O}}$ is unity, the stoichiometric or molal ionic product will be about twice that in pure water. However, $p \mathrm{H}$ (so called) determined either electrometrically or with indicators is a measure of activity rather than of concentration of hydrogen ions and is more precisely denoted by $p a_{\mathrm{H}}$ (Sørensen \& Linderstrøm-Lang; cf. Clark, 1928, p. 479). Again the majority of physico-chemical computations in aqueous media involve activities of hydrogen and hydroxyl ions and not molal concentrations. Since the uncertainty as to the value of the thermodynamic ionic product, $K_{w}=\frac{a_{\mathrm{H}^{+}} a_{\mathrm{OH}^{-}}}{a_{\mathrm{H}_{2} \mathrm{O}}}$, has been removed by the highly accurate and consistent work of Harned and his collaborators, this may be applied as it stands to our sea-water problems.

The activity of the water itself, $a_{\mathrm{H}_{2} \mathrm{O}}$, which has still to be considered, may be evaluated from the depression of the freezing-point of sea water below pure water, $\Delta t^{\circ}$, by means of the Lewis \& Randall equation (1923, p. 284):

$$
\log _{10} a_{\mathrm{H}_{2} \mathrm{O}}=-0.0042 \mathrm{II} \Delta t-0.0000022 \Delta t^{2} \text {. }
$$


The necessary freezing-point data were determined by Matthews (I923, p. 667). For a range of chlorinities the values of $a_{\mathrm{H}_{2} \mathrm{O}}$ calculated from equation (Io), are given in Table II.

Table II. The Activity of WAteR, $a_{\mathrm{H}_{2} \mathrm{O}}$, IN SEA WAteR

$\begin{array}{rrc}\mathrm{Cl} \% 0 & \Delta t{ }^{\circ} \mathrm{C} . & a_{\mathrm{H}_{2} \mathrm{O}} \\ 0 & 0.000 & \mathrm{I} \cdot 0000 \\ 5 & -0.483 & 0.9953 \\ 10 & -0.969 & 0.9906 \\ 15 & -1.466 & 0.9858 \\ 18 & -1.769 & 0.9830 \\ 19 & -1.872 & 0.9820 \\ 19 & -1.974 & 0.9810\end{array}$

The product of the ionic activities, $a_{\mathrm{H}^{+}} a_{\mathrm{OH}^{-}}$, is equal to $K_{w}$ only when $a_{\mathrm{H}_{2} \mathrm{O}}$ is unity as in pure water. In any aqueous solution the product

$$
\begin{aligned}
& K^{\prime}{ }_{w}=a_{\mathrm{H}^{+}} a_{\mathrm{OH}^{-}}=K_{w} a_{\mathrm{H}_{2} \mathrm{O}} ; \\
& \therefore p K^{\prime}{ }_{w}=p K_{w}-\log _{10} a_{\mathrm{H}_{2} \mathrm{O}} .
\end{aligned}
$$

In Table III are given values of $p K_{w}$ calculated from Harned \& Hamer's data (I933) and values of $p K^{\prime}{ }_{w}$ for sea water of $35 \%$ salinity and a range of

Table III. $p K_{w}$ For PURe Water and $p K^{\prime}{ }_{w}$ AND SOMe Values of $p a_{\mathrm{OH}}$

\begin{tabular}{|c|c|c|c|c|}
\hline \multirow{4}{*}{$t^{\circ} \mathrm{C}$} & \multirow{4}{*}{$\begin{array}{c}\text { Pure water } \\
p K_{w} \\
\text { I4.939 }\end{array}$} & \multicolumn{3}{|c|}{ Sea water at $35 \%$ salinity } \\
\hline & & \multirow{3}{*}{$\begin{array}{l}p K^{\prime} \\
\text { I } 4.947\end{array}$} & \multicolumn{2}{|c|}{$p a_{\mathrm{OH}}$ at } \\
\hline & & & $p a_{\mathrm{H}}=8.000$ & $p a_{\mathrm{H}}=8.300$ \\
\hline & & & 6.947 & $6 \cdot 647$ \\
\hline 5 & $1473 \mathrm{I}$ & I4.739 & 6.739 & 6.439 \\
\hline Io & I 4.533 & I $4.54 \mathrm{I}$ & $6.54 \mathrm{I}$ & $6 \cdot 24 \mathrm{I}$ \\
\hline I5 & I 4.345 & I4. 353 & 6.353 & 6.053 \\
\hline 20 & I 4.167 & I 4.175 & $6 \cdot 175$ & 5.875 \\
\hline 25 & I3.997 & 14.005 & 6.005 & 5.705 \\
\hline 30 & 13.832 & 13.840 & 5.840 & 5.540 \\
\hline
\end{tabular}
in Sea Water of $35 \%$ Salinity at a Range of Temperatures

temperatures calculated from equation (I2). It will be seen that the difference between $p K_{w}$ and $p K^{\prime}{ }_{w}$ is of importance only for work of the very highest accuracy. Since from equation (II)

$$
p a_{\mathrm{OH}}=p K^{\prime}{ }_{w}-p a_{\mathrm{H}},
$$

the value of $p a_{\mathrm{OH}}$ for a given sample of sea water can now be found with an accuracy equal to that of the measurement of $p a_{\mathrm{H}}$, providing that the salinity is known approximately and that the temperature is known to within $0 \cdot \mathrm{I}^{\circ} \mathrm{C}$. Values of $p K_{w}$ for intermediate temperatures may be found either by graphical interpolation or with great precision from Harned \& Hamer's equation (1933):

$$
p K_{w}=\frac{4787 \cdot 3}{T}+7 \cdot 1321 \log _{10} T+0.010365 T-22 \cdot 801 .
$$




\section{The Theoretical Oxidation-Reduction Potential}

Using these values for $\mathrm{E}^{\circ}, p_{0}$ and $a_{\mathrm{OH}^{-}}$, the following theoretical values for the oxidation-reduction potential of the oxygen system have been calculated by equation (2) (Table IV):

Table IV. Theoretical Oxidation-Reduction Potential of THE OXYGEN SySTEM IN Volts

\begin{tabular}{|c|c|c|c|c|}
\hline \multirow{3}{*}{$t^{\circ} \mathrm{C}}$. & \multicolumn{2}{|c|}{$\mathrm{O}_{2}=\mathrm{I00} \%$ saturation } & \multicolumn{2}{|c|}{$\mathrm{O}_{2}=\mathrm{IO} \%$ saturation } \\
\hline & pH 8.०० & $p \mathrm{H} \mathrm{8.30}$ & $p \mathrm{H} 8.00$ & $p \mathrm{H} 8.30$ \\
\hline & 0.804 & 0.788 & 0.790 & 0.774 \\
\hline I5 & 0.767 & 0.750 & 0.753 & 0.735 \\
\hline 25 & 0.742 & 0.724 & 0.727 & 0.710 \\
\hline
\end{tabular}

Thus, decreasing the percentage saturation of oxygen from 100 to $10 \%$ or raising the $p \mathrm{H}$ by 0.30 unit will each lower the potential by $0.02 \mathrm{~V}$. only. Similarly, raising the temperature by $10^{\circ} \mathrm{C}$. will lower the potential by $0.025 \mathrm{~V}$. Thus variations in oxygen concentration, $p \mathrm{H}$ and temperature within the limits usually found cannot affect the potential by more than about O. IO V. at most.

We see, therefore, that if the oxidation-reduction potential of sea water is due to a reversible oxygen system, then the potential will lie between 0.7 and $0.8 \mathrm{~V}$. This theoretical discussion has served to clear the ground by giving us values for the reversible potential, $\mathrm{E}^{\mathrm{h}}$, which we can now discuss further in the light of certain peculiar properties possessed by the oxygen electrode.

\section{The Irreversible Oxidation-Reduction Potential of SEA WATER}

Of prime importance is the practical difficulty involved in measuring the potential at an oxygen electrode. Oxygen electrodes tend to be irreversible, do not obey the thermodynamic relationship between electrode potential and partial pressure of oxygen, and are readily polarized even by minute currents. From a careful examination Hoar (I933) concluded that the platinum used in the electrode forms an oxide film, but that the irreversibility results not so much from the presence of this film but, due to crack formation, to its permeability to the electrolyte which results in self-polarization.

Due to this irreversibility, determinations of the potential by different workers vary considerably. Hoar (I933) has found the potentials of a saturated oxygen electrode against a hydrogen electrode in the same solution, $\mathrm{E}_{\beta}$, which should be typical of results obtained with a bright platinum electrode under good working conditions. The difference between the reversible and irreversible potentials of an oxygen electrode will be the same, no matter what halfcell is used as reference electrode so that

Reversible potential against hydrogen in same solution, $\mathrm{E}_{\alpha}$, minus Irreversible potential against hydrogen in same solution, $\mathrm{E}_{\beta}$; equals Reversible 
potential against normal hydrogen electrode, $\mathrm{E}_{\gamma}$, minus Irreversible potential against normal hydrogen electrode, $\mathrm{E}_{\delta}$.

$$
\therefore \mathrm{E}_{\delta}=\mathrm{E}_{\gamma}-\mathrm{E}_{\alpha}+\mathrm{E}_{\beta} \text {. }
$$

In Table V Hoar's observed values of $\mathrm{E}_{\beta}$ are given in column 3 together with the calculated theoretical values of $E_{\gamma}$. Since $E_{\alpha}=I \cdot 2256 \mathrm{~V}$. (Lewis \& Randall, I923, pp. 408 and 487 ), $\mathrm{E}_{\delta}$ can be readily computed. The $p \mathrm{H}$ values in $\mathrm{N} /$ IO $\mathrm{H}_{2} \mathrm{SO}_{4}$ and $\mathrm{N} /$ Io $\mathrm{NaOH}$ have been calculated from the activity coefficients given by Harned \& Hamer (I935) and Harned \& Hecker (I933).

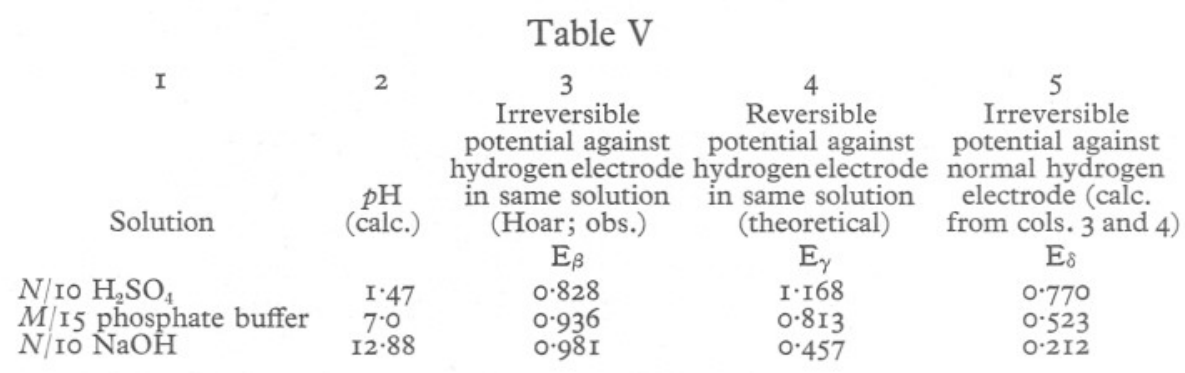

Dr W. R. G. Atkins has very kindly undertaken determinations of the oxidation-reduction potential of sea water, $\mathrm{E}^{\mathrm{h}}$, using bright platinum electrodes which had barely cooled, after having been heated to redness right in a methylated spirit flame. The potentials were measured against a calomel $(N /$ IO $\mathrm{KCl})$ half-cell which has a potential against the normal hydrogen electrode of $0.338 \mathrm{~V}$. He found that the potential of sea water lies in the neighbourhood of $0.43 \mathrm{~V}$. Determinations were also made of the $\mathrm{E}^{\mathrm{h}}$ and $p \mathrm{H}$ of sea water acidified with varying amounts of hydrochloric acid. Following the immersion of the electrodes the potential fell away rapidly so that the initial readings were taken as most nearly correct. After the apparatus had been improved enabling several seconds to be saved before making this initial reading, a second series was made which lay somewhat higher than the first. Values of $\mathrm{E}^{\mathrm{h}}$ corresponding to the experimental $p \mathrm{H}$ values have also been read from a curve constructed from Hoar's data (Table V) and are included in Table VI for comparison with Atkins' results which have been rounded off to the nearest centivolt owing to the uncertainty inherent in the measurement. It will be seen that the agreement is considerably better than might have been expected. Furthermore, Heintze (I935) has collected all the evidence available on the $\mathrm{E}^{\mathrm{h}}$ of soil solutions and has shown that at $p \mathrm{H} 8.0$ most of the values fall between $\mathrm{E}^{\mathrm{h}} 0.4$ and $0.5 \mathrm{~V}$., and that the potential of a standard buffer solution at $p \mathrm{H} 8$ lay at about $0.45 \mathrm{~V}$. Thus these measurements also were those of an irreversible oxygen electrode.

It is clear, therefore, that in sea water, the oxidation-reduction potential is governed solely by this irreversible oxygen system. The conclusion is almost certainly of general applicability, so that it should be unnecessary to repeat the 


\section{Table VI. Oxidation-Reduction Potential of Sea Water, E $^{\text {h }}$, in Volts at a Range of $p$ H Values}

\begin{tabular}{|c|c|c|c|}
\hline \multirow[b]{2}{*}{$p \mathrm{H}$} & \multirow{2}{*}{$\begin{array}{c}\mathrm{E}^{\mathrm{h}} \text { of oxygen electrode } \\
\text { in water at } 25^{\circ} \mathrm{C} \text {. } \\
\text { (derived from Hoar's } \\
\text { results) }\end{array}$} & \multicolumn{2}{|c|}{$\begin{array}{l}\mathrm{E}^{\mathrm{h}} \text { of an air electrode in sea water } \\
\text { at } 15^{\circ} \mathrm{C} \text {. }\end{array}$} \\
\hline & & Ist series & 2nd series \\
\hline$I .09$ & 0.79 & 0.78 & - \\
\hline 2.05 & 0.75 & 0.75 & 0.80 \\
\hline $2 \cdot 14$ & 0.75 & 0.70 & 0.76 \\
\hline $2 \cdot 58$ & 0.73 & 0.69 & 0.76 \\
\hline 3.09 & 0.71 & 0.66 & 0.73 \\
\hline 3.55 & 0.69 & 0.67 & 0.72 \\
\hline 6.87 & 0.53 & 0.57 & 0.47 \\
\hline $7 \cdot 14$ & 0.52 & 0.45 & 0.45 \\
\hline 8.15 & 0.46 & 0.42 & 0.44 \\
\hline
\end{tabular}

The potential in water saturated with oxygen at $25^{\circ} \mathrm{C}$. should lie close to the potential in water saturated with air at $15^{\circ} \mathrm{C}$. If the reversible laws can be applied:

$$
\mathrm{E}^{\mathrm{h}}\left(\text { air, } \mathrm{I} 5^{\circ} \text { C. }\right)=\mathrm{E}^{\mathrm{h}}\left(\mathrm{O}_{2}, 25^{\circ} \text { C. }\right)-0.02 \mathrm{I}+0.002 \mathrm{pH} \text {. }
$$

work on sea water from other regions unless there is a strong suspicion that reducing substances able to impart poise to sea water are present.

Although the divergence of the experimental from the theoretical potential is due in the first place to the formation of an oxide film on the electrode, Hoar considers that even with a perfectly inert metal electrode, should such ever be found, the theoretical reversible potential could never be quite reached owing to the extreme sluggishness of the reaction: oxygen $\rightleftharpoons$ hydroxyl-ion. Much more work is required before this point of view, which is not in complete accord with present ideas of ionic reactions, may be taken as established.

Oxidation-reduction potentials lower than that of the irreversible oxygen electrode may well be found off the west African coast in $10^{\circ} \mathrm{S}$. latitude, where Wattenberg (1933) found partial pressures of carbon dioxide more than four times that in the atmosphere and where extensive breakdown of organic material is taking place. If the irreversible oxygen potential should be found to prevail in that or similar regions, it may be expected to prevail throughout the open ocean. Since conditions of temperature, partial pressure of carbon dioxide $\left(P_{\mathrm{CO}_{2}}\right)$ and $p \mathrm{H}$ are as extreme at Meteor Station $\mathrm{I} 88$ as at any place that has as yet been fully investigated it is of interest to evaluate the $p \mathrm{OH}$ (strictly speaking, $p a_{\mathrm{OH}}$ ) in situ and the reversible oxidation-reduction potential based on the oxygen system (Table VII). In spite of the great depletion of oxygen around $400 \mathrm{~m}$. the temperature remains the dominant factor and the reversible potential increases steadily right through the stratum of stagnant water.

Reactions which depend on the activity of hydroxyl ion in situ $\left(p \mathrm{OH}_{t}\right)$ will be affected by the change in $p K^{\prime}{ }_{w}$ as well as in $p \mathrm{H}_{t}$. Thus although the values of $p \mathrm{H}_{t}$ at 25 and $1980 \mathrm{~m}$. are similar the values of $p \mathrm{OH}_{t}$ differ by 0.75 unit. On account of this, ferric hydroxide, for example, would be more than 200 times as soluble at the greater depth and, in general, solubilities dependent on $p \mathrm{OH}$ will be much affected. 
Table VII. Station i88 of the Meteor Expedition on September 5 I926 IN $8^{\circ} 58 \cdot 0^{\prime}$ S., $8^{\circ} 57 \cdot 7^{\prime}$ E. (Wattenberg, I933, pp. 72 and 292). Columns marked with an asterisk contain Wattenberg's data; the remaining columns include data calculated from these

\begin{tabular}{|c|c|c|c|c|c|c|c|c|}
\hline $\begin{array}{l}\text { True } \\
\text { depth } \\
\text { m.`}\end{array}$ & ${ }^{\text {Temp. }}{ }^{\star}{ }^{\star}$ & $\mathrm{PCO}_{2} \times \mathrm{IO}^{4 \star}$ & $p \mathrm{H}_{t} \dagger^{\star}$ & $p^{\prime} K_{w}$ & $p \mathrm{OH}_{t} \dagger$ & $\begin{array}{c}\mathrm{O}_{2} \\
\text { c.c. } / 1 \text {. }^{\star}\end{array}$ & $\begin{array}{l}\mathrm{E}^{\circ} \\
\mathrm{V} .\end{array}$ & $\begin{array}{c}\mathrm{E}^{\mathrm{h}} \\
\text { (reversible) } \\
\mathrm{V} .\end{array}$ \\
\hline 0 & $22 \cdot 4$ & $3 \cdot 2$ & $8 \cdot 15$ & I $4 \cdot$ IO & $5 \cdot 95$ & $4 \cdot 8 \mathrm{I}$ & 0.4017 & 0.740 \\
\hline 25 & $2 I \cdot 0$ & $3 \cdot 7$ & 8.09 & $\mathrm{I} 4 \cdot \mathrm{I} 4$ & 6.05 & $4 \cdot 52$ & 0.4043 & 0.746 \\
\hline 50 & $16 \cdot 2$ & $6 \cdot 1$ & 7.91 & $\mathrm{I} 4.3 \mathrm{I}$ & $6 \cdot 40$ & $\mathrm{I} \cdot 40$ & 0.4120 & $0.76 \mathrm{I}$ \\
\hline IOO & I 4.3 & $6 \cdot 9$ & $7 \cdot 86$ & 14.38 & $6 \cdot 52$ & $\mathrm{I} \cdot 40$ & 0.4148 & 0.768 \\
\hline I95 & $\mathrm{I} 2 \cdot 2$ & $8 \cdot 4$ & $7 \cdot 78$ & $\mathrm{I} 4 \cdot 46$ & 6.68 & 0.88 & 0.4183 & 0.775 \\
\hline 395 & $8 \cdot 5$ & $12 \cdot 2$ & $7 \cdot 62$ & $14 \cdot 60$ & $6 \cdot 98$ & 0.45 & 0.4242 & 0.788 \\
\hline 590 & $5 \cdot 8$ & 10.7 & $7 \cdot 66$ & I 4.71 & 7.05 & $\mathrm{I} \cdot 43$ & 0.4285 & 0.800 \\
\hline 785 & $4 \cdot 5$ & $8 \cdot 2$ & $7 \cdot 76$ & $14 \cdot 76$ & 7.00 & $2 \cdot 72$ & 0.4306 & $0.80 \mathrm{I}$ \\
\hline 990 & $4 \cdot I$ & $7 \cdot \mathrm{I}$ & $7 \cdot 8 I$ & 14.78 & $6 \cdot 97$ & $3 \cdot 22$ & 0.4312 & $0.80 I$ \\
\hline I980 & $3 \cdot 3$ & $4 \cdot I$ & 8.01 & $14.8 \mathrm{I}$ & 6.80 & 5.06 & 0.4325 & 0.793 \\
\hline
\end{tabular}

\section{BIOLOGICAL IMPLICATIONS}

The implications of the irreversibility of the oxygen electrode system for a study of sea water as a biological environment must now be discussed. Two facts are clear: (i) under no circumstances will the oxygen system function strictly reversibly, but (ii) we are not concerned with a metal electrode which may form porous oxide films. From a system functioning irreversibly less free energy can be got than from the same system functioning reversibly. In consequence the effective oxidation potential will be lower, for this is merely another way of describing the free-energy state of the system, but it does not follow that the biologically effective potential need be as low as that found with a platinum electrode. The effective $\mathrm{E}^{\mathrm{h}}$ may vary considerably with the system under investigation according to the greater or less degree of irreversibility of its reaction with oxygen.

The ferric-ferrous system, which is of importance for other investigations in progress here, is recognized as not being very sensitive to oxygen. It has been most studied in the $p \mathrm{H}$ range $0-2$, where its oxidation-reduction potential is independent of $p \mathrm{H}$ and lies only just below that of the irreversible oxygen electrode. The driving force of the reaction of dissolved oxygen with ferrousion is therefore small. Moreover, the resulting ferric-ion collects in solution tending to reverse the direction of the reaction. In our problem we are concerned with iron in sea water at $p \mathrm{H} 8$; at this $p \mathrm{H}$ the very low solubility of ferric hydroxide results in the removal of ferric-ion from solution as fast as it is formed. In consequence the tendency for ferrous-ion to be oxidized is enormously increased, and solutions of ferrous salts are very unstable and a state approaching equilibrium is rapidly attained. It appears reasonable to extend these conceptions to the very small amounts of iron present in sea water. 
This paper has been developed for the particular case of sea water, but the treatment is general and may be extended to all aerated natural waters. In many cases where reducing substances are definitely known not to be present, it may well be sufficiently accurate to read off the irreversible potential from a curve constructed from Hoar's data and to calculate the theoretical reversible potential from equation (2). The potential for biological studies will lie somewhere between these limits; no electrometric measurements can give more information than this. Whilst there must always be some uncertainty in any work involving the oxidation-reduction potential of the oxygen system it is felt that, even so, knowledge of much importance on the behaviour of natural waters may be obtained. In many cases, such as those involving solubilities and the behaviour of multivalent metals, information may be obtained as to what conditions are and what are not possible. Such a case, the behaviour of iron in sea water, will be discussed in a subsequent paper.

\section{SUMMARY}

The activity of oxygen in sea water and standard oxygen electrode potentials at a range of temperatures have been computed.

Accurate values for the thermodynamic ionic product of water, $K_{w}$, found by Harned \& Hamer, have been applied to the calculation of the activity of hydroxyl ion in sea water from $p \mathrm{H}$ measurements.

The activity of water in sea water has been computed from the lowering of the freezing-point.

From these data the theoretical reversible oxidation-reduction potential of sea water has been calculated.

Typical data for the irreversible potential in the $p \mathrm{H}$ range I- 8 have been derived from Hoar's results with which experimental determinations made by Dr Atkins agree. Thus the oxidation-reduction potential of sea water is controlled solely by the oxygen system.

The biological implications of the reversible and irreversible (at platinum electrode) potentials is discussed. Under no circumstances will the oxygen system function strictly reversibly, but on the other hand we are not necessarily concerned with metal electrodes which form porous oxide films. It is considered that in sea water the potential effective in systems of biological importance may lie anywhere between 0.43 and $0.75 \mathrm{~V}$., the irreversible ( $\mathrm{Pt}$ electrode) and reversible potentials.

I am much indebted to Prof. H. T. S. Britton, Exeter, for critical discussion of the subject-matter of this paper and for reading the manuscript. I must, however, be held responsible for the views put forward. 


\section{REFERENCES}

ClARK, W. M., I928. The Determination of Hydrogen Ions. London, I928. Third edition.

HARned, H. S. \& HAMER, W. J., I933. The ionization constant of water and the dissociation of water in potassium chloride solutions from electromotive forces of cells without liquid junction. Fourn. Amer. Chem. Soc., Vol. 55, pp. 2194-206.

- I935. The thermodynamics of aqueous sulfuric acid solutions from electromotive force measurements. Fourn. Amer. Chem. Soc., Vol. 57, pp. 27-33.

HARned, H. S. \& HeCKer, J. C., I933. The thermodynamics of aqueous sodium hydroxide solutions from electromotive force measurements. Fourn. Amer. Chem. Soc., Vol. 55, pp. 4838-49.

HeINTZE, S. G., I935. Soil oxidation-reduction potentials and $p \mathrm{H}$ values. Soil Research (Bodenkundliche Forschungen), Vol. 4, pp. 35I-5.

HoAR, T. P., I933. The mechanism of the oxygen electrode. Proc. Roy. Soc. London, A, Vol. I42, pp. 628-46.

Keys, A., Christensen, E. H. \& KROGH, A., I935. The organic metabolism of sea water with special reference to the ultimate food cycle in the sea. Fourn. Mar. Biol.Assoc., Vol. xx, pp. I8I-96.

Lewis, G. N. \& Randall, M., 1923. Thermodynamics. New York and London: McGraw Hill.

Matthews, D. J., 1923. Physical Oceanography. Dictionary of Applied Physics, Vol. III, pp. 665-92. London: Macmillan \& Co.

Reiss, P. \& Vellinger, E., I929. Le potentiel d'arrêt des divisions de l'œuf d'Oursin. Arch. Phys. Biol., Vol. 7, pp. 80-Ior.

Wattenberg, H., I933. Wiss. Ergebn. Deutsch. Atlantisch. Exped. Meteor, 1925-7, Bd. viII. 